\title{
Effect of graphite and common rubber plasticizers on properties and performance of ceramizable styrene-butadiene rubber-based composites
}

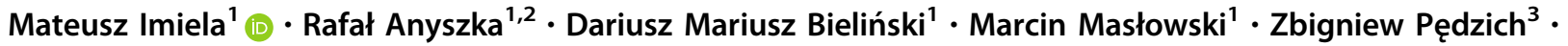 \\ Magdalena Ziąbka ${ }^{3} \cdot$ Przemysław Rybiński $^{4} \cdot$ Bartłomiej Syrek $^{4}$
}

Received: 19 December 2018/Accepted: 27 April 2019/Published online: 21 May 2019

(c) The Author(s) 2019

\begin{abstract}
Ceramizable composites are highly filled polymer dispersion composites which create stiff porous and durable ceramic structure when exposed to fire or elevated temperature. However, the incorporation of large amounts of mineral fillers into the composites strongly decreases their processing performance. In order to improve extrusion properties of these composites, plasticizers like triethylamine, ethylene glycol, naphthalene, dibutyl phthalate and graphite were used. Extrudability of the composite mixes was examined as an indicator of their processing performance. After the vulcanization, mechanical properties of the composites were tested. In order to check the micromorphology of the samples scanning electron microscopy was performed. Because of the significant flammability of the plasticizers, it was also important to examine how these additives change combustion behavior of the composites by cone calorimetry. Additionally, composites were ceramized in three different thermal conditions and their compression strength was measured. The incorporation of graphite platelets resulted in optimum balance between enhancing extrudability and preserving satisfactory mechanical properties and ceramization performance. The obtained results showed that ceramizable composites are susceptible to plasticizing and their mechanical and combustibility properties can be preserved like before the plasticizers addition.
\end{abstract}

Keywords Polymer composites · Ceramization - Caramification · Styrene-butadiene rubber · Plasticizer . Graphite

Electronic supplementary material The online version of this article (https://doi.org/10.1007/s10973-019-08339-w) contains supplementary material, which is available to authorized users.

\section{Introduction}

Along with metallic and ceramic materials, polymeric materials have become the basic structural materials produced by man. Despite their popularity, it should be remembered that one of the greatest disadvantages of polymeric materials is their flammability. For that reason, polymer materials should contain an effective flame-retardant

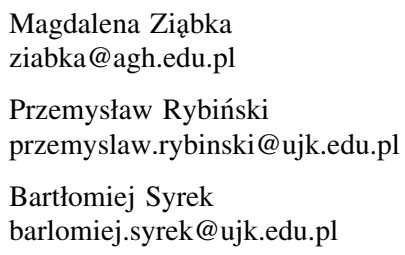

Extended author information available on the last page of the article

Marcin Masłowski marcin.maslowski@p.lodz.pl

Zbigniew Pędzich pedzich@agh.edu.pl 
system [1-3]. It is of great importance since a significant amount of these materials is widely used in public buildings, for example in wire covers, floor coverings or window and door frames and seals. One of the many approaches to significantly reduce the flammability of polymeric materials is to incorporate a large amount of properly designed mix of fillers that promote the ceramization process. This results in the formation of a continuous ceramic structure which exhibits high fire and thermal protection.

Ceramization process has been widely described in the literature. This process involves the creation of a stiff, durable and porous ceramic structure during the heat treatment of highly filled polymer composites [4-8]. The best-known type of a polymer used to create ceramizable composites is silicone rubber [9-12]. When silicone rubber decomposes in oxidative atmosphere, it creates amorphous silica that strengthens the ceramic phase. The structure obtained can block the propagation of flames and decreases the rate of the formation of flammable fuel products, originated from the thermooxidative destruction of polymer matrix. The main mechanism of the ceramic structure formation involves the amorphous fluxing agent the addition of, which softens at high temperature and integrates thermally stable mineral filler particles and solid products created during the polymer decomposition [13-17].

Recently, ethylene-vinyl acetate copolymer (EVA) has been introduced as a continuous phase for ceramizable composites [18-21]. We proposed an alternative solution consisting in the application of styrene-butadiene rubber (SBR) as polymer matrix for ceramizable composites $[22,23]$. Firstly, it entails lower costs than silicone and is widely available. Secondly, SBR is the second, after natural rubber, most used elastomer on the market. What is more, SBR can be filled with a higher amount of functional fillers (even up to $350 \mathrm{phr}$ ), which is far more in comparison with PDMS (100 phr) or EVA (150 phr), without a significant decrease in its mechanical properties and processability. These properties enhance the creation of stronger ceramic structures of lower gas permeability. Recently, ethylenepropylene-diene rubber (EPDM) and nitrile rubber (NBR) have been also tested as elastomer matrices for ceramizable composites [24-26]. However, the composites properties are still far from satisfactory and require further research.

Rubber composites are commonly plasticized in order to improve the processing properties [27, 28]. Some polymers like poly(vinyl chloride) (PVC) are usually used with a high amount of plasticizers (PPVC) [29]. These plasticized types of polymers can be modified by carbon fillers like graphite, graphene or carbon nanotubes [30,31]. When a filler is added to an elastomer matrix, the viscoelastic properties change because of two types of intrinsic interactions: (1) filler-polymer macromolecules interactions, which are related to mutual compatibility of the filler and rubber, additionally an effect of rubber occlusion might take place, in which the polymer is closed in-between or inside filler aggregates; (2) filler-filler interactions, at sufficiently high amount of filler incorporated it is creating an internal reinforcing network. This network plays a crucial important role in the rubber reinforcement effect and is capable of transmitting mechanical stresses. The incorporation of fillers into the rubber matrix results in a changing of the linear dependence of the storage shear modulus in the function of deformation into nonlinear [32]. The dynamic properties of the filled rubber depend on the amplitude of deformation, in which it is possible to observe the Payne effect resulting from filler to filler interactions that is not depended on the polymer matrix.

In this study, we investigated the effect of various plasticizers on SBR-based ceramizable composites' extrudability, mechanical properties, flammability and ceramization performance in order to improve their processability simultaneously preserving their other properties at a satisfactory level.

\section{Experimental}

\section{Materials}

The elastomer matrix - styrene-butadiene rubber synthesized by employing the emulsion method (e-SBR), trade name KER 1500, was purchased from Synthos S.A., Oswiecim, Poland. The rubber contained 22-25 mass $\%$ of bonded styrene, 5.0-7.5 mass $\%$ of organic acids, max. 0.7 mass $\%$ of volatile matters, max. 0.4 mass $\%$ of soaps and max. 0.4 mass $\%$ of total ash. Its viscosity (ML $1+4 ; 100{ }^{\circ} \mathrm{C}$ ) equals $45 \div 55^{\circ} \mathrm{ML}$. The antioxidant (2,2,4-trimethyl-1,2-dihydroquinoline (TMQ)) and cross-linking activators (stearic acid, $\mathrm{ZnO}$ ), accelerator (N-cyclohexyl-2-benzothiazole sulfenamide (CBS)) and curing agent (sulfur) were purchased from Torimex-Chemicals Ltd. Sp. z o. o., Konstantynów Łódzki, Poland. The ceramization-promoting glass frit "A 4015 " of chemical composition (mass\%): $4 \mathrm{Li}_{2} \mathrm{O}, 16 \mathrm{Na}_{2} \mathrm{O}$, $37 \mathrm{~B}_{2} \mathrm{O}_{3}, 43 \mathrm{SiO}_{2}$ and softening point temperature of $540{ }^{\circ} \mathrm{C}$ was originated from Reimbold and Strick $\mathrm{GmbH}$, Cologne, Germany. Mica (phlogopite) "PW30" (specific surface area of $2.8 \mathrm{~m}^{2} \mathrm{~g}^{-1}$ ) produced by LKAB Minerals $\mathrm{GmbH}$ (Lulea, Sweden) was used as a mineral filler for ceramic layer reinforcement. The following plasticizers were used to improve viscoelastic properties, namely triethylamine [TEA], ethylene glycol [glycol], naphthalene, dibutyl phthalate [DBP], graphite PMM-11/99,5 (grain size $50 \mu \mathrm{m}$ ) produced by KOH-INOOR GRAFIT s.r.o. Czech Republic.

\section{Preparation of the samples}

The composite mixes (Table 1A) were prepared using the two roll laboratory mill (roll length-200 mm; diameter- 
Table 1 Composition (in phr-mass parts per hundred parts of rubber) and vulcanization parameters of the ceramizable composites mixes

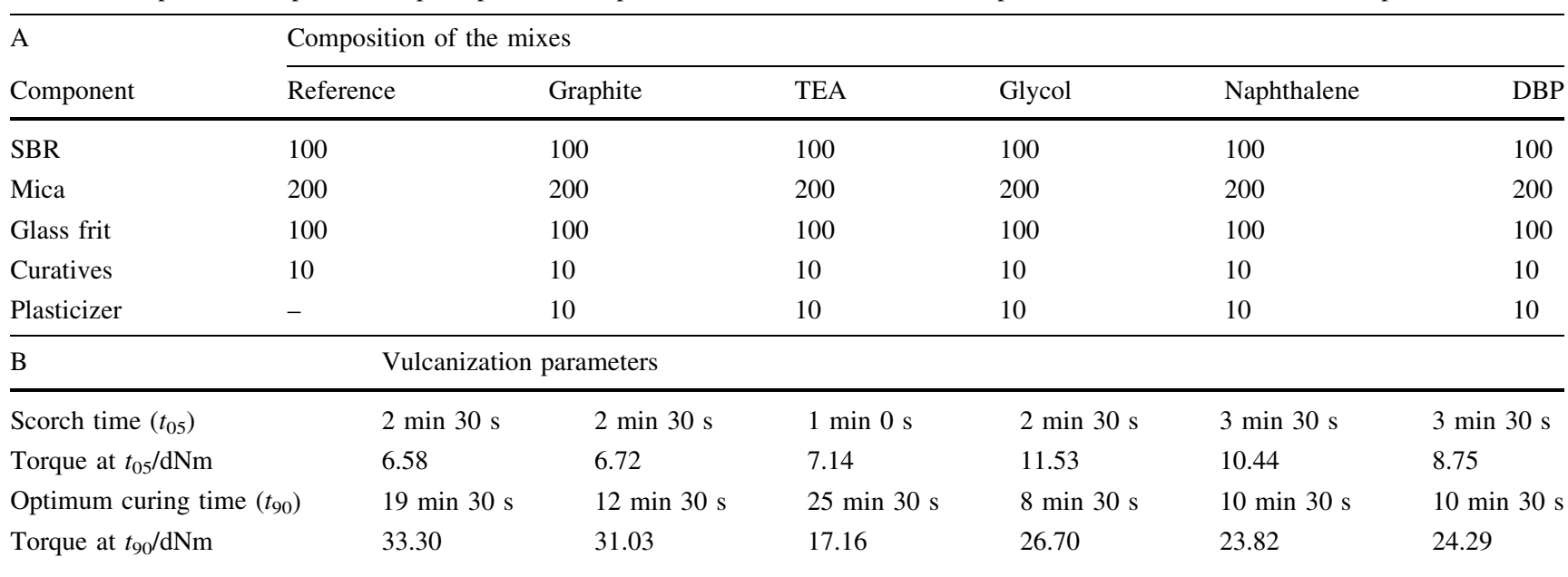

$150 \mathrm{~mm}$ ) (Bridge, UK), working with friction of 1.1 and rotational speed of the slower roll $18 \mathrm{rpm}$ and $20 \mathrm{rpm}$ of the faster roll. The kinetics of vulcanization of the composite mixes was tested using the rheometer Alpha Technologies MDR2000 according to PN-ISO 37:1998. In accordance to the obtained results (Table 1B), the samples were formed and vulcanized in steel molds by a laboratory press at $160{ }^{\circ} \mathrm{C}$ and $10 \mathrm{MPa}$ of pressure.

\section{Techniques}

The extrudability tests of the composite mixes were performed at the temperature of $100{ }^{\circ} \mathrm{C}$ and with rotor speed of $45 \mathrm{rpm}$ by Brabender Plasticorder (Brabender $\mathrm{GmbH} \&$ Co KG, Germany) laboratory extruder.

Mechanical properties of the vulcanizates were tested before and after vulcanization by Zwick/Roell 1435 testing machine, and Zwick/Roell hardness test (Germany) - before ceramization.

Combustibility of the vulcanizates was determined by means of cone calorimeter (Fire Testing Technology Ltd., East Grinstead, UK). The samples with dimensions $100 \mathrm{~mm}$ x $100 \mathrm{~mm}$ × $2 \mathrm{~mm}$ were placed horizontally toward the heating source of $35 \mathrm{~kW} \mathrm{~m}^{-2}$.

Micromorphology of the cross sections of the vulcanizates before ceramization was examined by FEI Nova SEM 200 scanning electron microscope.

Thermally induced ceramization of the vulcanizates was performed in the laboratory furnace FCF 2.5SM (Czylok, Poland). Cylindrical samples (diameter-16 mm, height$8 \mathrm{~mm}$ ) of the composites were heated in three different conditions: (1) $1100{ }^{\circ} \mathrm{C}$-from room temperature to $1100{ }^{\circ} \mathrm{C}$ in $30 \mathrm{~min}$ (heating rate $35^{\circ} \mathrm{C} \mathrm{min}^{-1}$ ), (2) $950{ }^{\circ} \mathrm{C}$-from room temperature to $950{ }^{\circ} \mathrm{C}$ in $120 \mathrm{~min}$ (heating rate $7.5^{\circ} \mathrm{C} \mathrm{min}{ }^{-1}$ ), (3) $550-1000{ }^{\circ} \mathrm{C}$ - form room temperature to $550{ }^{\circ} \mathrm{C}$ in $53 \mathrm{~min}$ (heating rate $10{ }^{\circ} \mathrm{C} \mathrm{min}^{-1}$ ), $10 \mathrm{~min}$ of isothermal conditions in $550{ }^{\circ} \mathrm{C}$ and at the end heating from $550{ }^{\circ} \mathrm{C}$ to $1000{ }^{\circ} \mathrm{C}$ in $27 \mathrm{~min}$ (heating rate $16{ }^{\circ} \mathrm{C} \mathrm{m^{-1 }}{ }^{-}$_ total time $90 \mathrm{~min}$.

\section{Results and Discussion}

\section{Appearance of the samples after extrusion}

Extrusion of highly filled elastomer composite mixes is an extremely challenging problem. These materials have a high value of viscosity and do not able to maintain a coherent structure because of large filler/elastomer

(a)
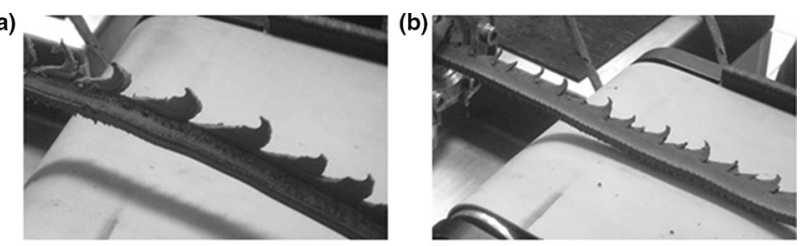

(c)

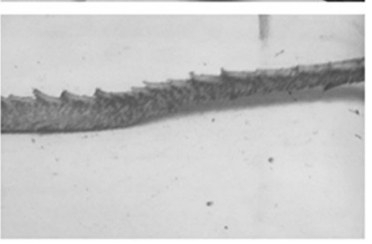

(e)
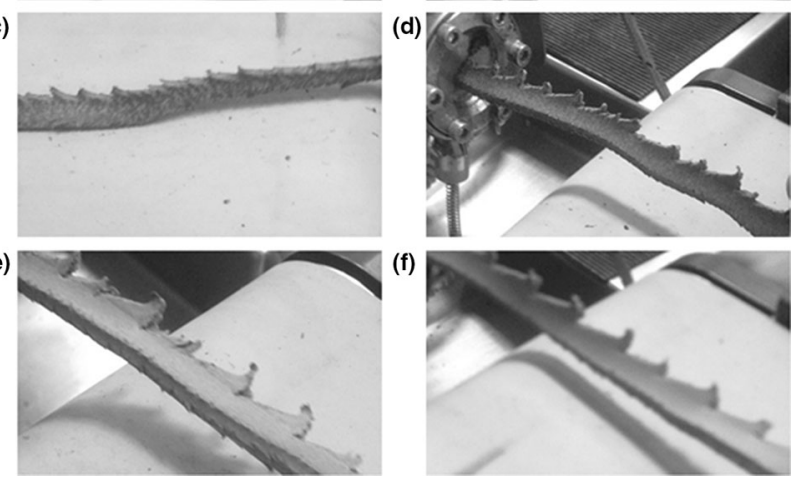

Fig. 1 Appearance of the composite mixes after the extrusion: reference (a), graphite (b), TEA (c) glycol (d), naphthalene (e), DBP (f) 
Table 2 Mechanical properties of the vulcanizated composites: tear resistance (TES) stress at $100 \%$ (SE100), 200\% (SE200) and $300 \%$ (SE300) of elongation, tensile strength (TS), elongation at break (Eb) and shore hardness, scale D

\begin{tabular}{|c|c|c|c|c|c|c|}
\hline Parameter & Reference & Graphite & TEA & Glycol & Naphthalene & DBP \\
\hline $\mathrm{TES} / \mathrm{N} \mathrm{mm^{-1 }}$ & $22 \pm 2$ & $24 \pm 2$ & $22 \pm 2$ & $28 \pm 2$ & $26 \pm 2$ & $27 \pm 1$ \\
\hline SE100/MPa & $3.2 \pm 0.1$ & $3.9 \pm 0.2$ & $2.2 \pm 0.2$ & $3.9 \pm 0,1$ & $2.8 \pm 0.1$ & $2.9 \pm 0.1$ \\
\hline SE200/MPa & $3.4 \pm 0.1$ & $4.1 \pm 0.2$ & $2.2 \pm 0.4$ & $4.0 \pm 0.1$ & $2.9 \pm 0.1$ & $3.0 \pm 0.1$ \\
\hline SE300/MPa & $3.7 \pm 0.1$ & - & $2.4 \pm 0.5$ & $4.4 \pm 0.1$ & $3.2 \pm 0.1$ & $3.3 \pm 0.2$ \\
\hline $\mathrm{TS} / \mathrm{MPa}$ & $4.7 \pm 0.1$ & $4.4 \pm 0.1$ & $3.4 \pm 0.2$ & $4.5 \pm 0.1$ & $4.1 \pm 0.3$ & $4.1 \pm 0.5$ \\
\hline $\mathrm{Eb} / \%$ & $449 \pm 11$ & $257 \pm 56$ & $495 \pm 17$ & $301 \pm 115$ & $456 \pm 34$ & $427 \pm 28$ \\
\hline Hardness $/{ }^{\circ} \mathrm{ShD}$ & $22 \pm 1$ & $23 \pm 1$ & $17 \pm 1$ & $24 \pm 1$ & $19 \pm 1$ & $21 \pm 1$ \\
\hline
\end{tabular}

interfacial energy differences between the non-polar SBR elastomer and the mineral fillers of polar surface properties. Therefore, the extrusion flow of the mixes is disturbed by the local stress concentration resulting in delamination/ tearing of the mixes. The pictures of the extruded composite mixes are presented in Fig. 1.

All of the composite mixes exhibit various shape deformations after the extrusion. However, after the addition of any plasticizer one observes a milder or greater improvement in the mixes' extrudability. From all the prepared composite mixes, the TEA composite exhibits the best extrusion performance. The deformations visible on the surface of the TEA extruded ribbon are significantly smaller. The rest of the plasticized composite mixes are still exhibiting a better shape coherency than the reference composite mix. However, they still are not satisfactory.

\section{Mechanical properties of composites before ceramization}

The mechanical properties of the composite vulcanizates are presented in Table 2.

The tensile strength value of the composites with plasticizers is lower than for the reference sample. The TEA sample shows the worst properties, for which one can see a deterioration of $28 \%$ in its TS in comparison with the reference sample. However, on the other hand, the TEA composite brakes at almost $500 \%$ of elongation exhibiting an enhanced elastic performance. The graphite composite is characterized by the lowest value of elongation at break since graphite is the only solid-state plasticizer utilized in this work that exhibits an alternative mechanism of plasticization based on effortless displacement of graphene layers among each other in the graphite particle. The static tensile results suggest that the graphite particles exhibit strong interactions with the SBR polymer matrix, possibly between the aromatic graphene sheets and aromatic rings from styrene mers of the SBR rubber [33]. This makes the graphite composite stiffer than the rest of the composites. (Only the composite with ethylene glycol exhibits similar mechanical properties.) This indicates that it is possible to preserve the stiffness of the composites simultaneously enhancing their extrudability by using these plasticizers. The opposite is observed in the case of the TEA composite-this plasticizer reduces filler-filler and filler-polymer interactions to the highest level. Therefore, this composite is the most elastic of all materials tested. Hardness tests confirm the results obtained in the static strain study. The results obtained for reference, graphite, glycol and DBP composites are almost the same, and they lie within the limits of statistical error. Only the composites TEA and naphthalene are characterized by lower values of hardness because the strongest plasticizing effect originated from plasticizers tested. (a')

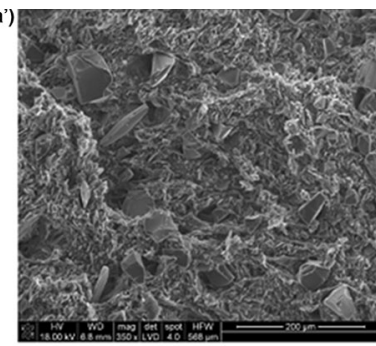

(b')

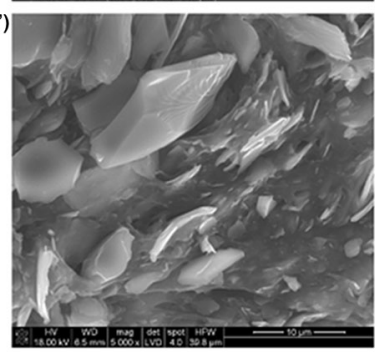

(c') एक

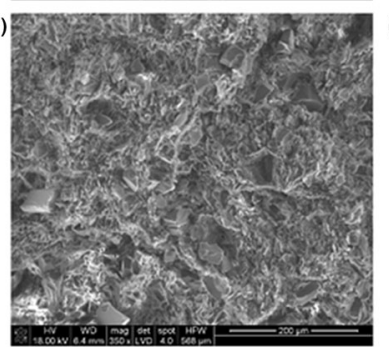

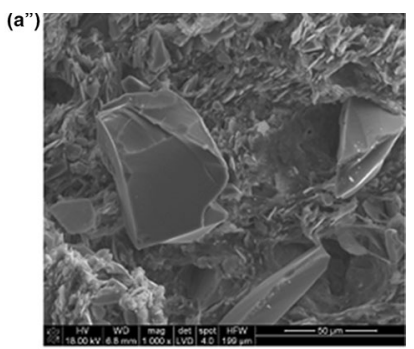

(b")

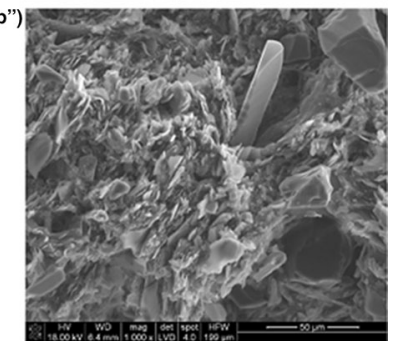

(c")

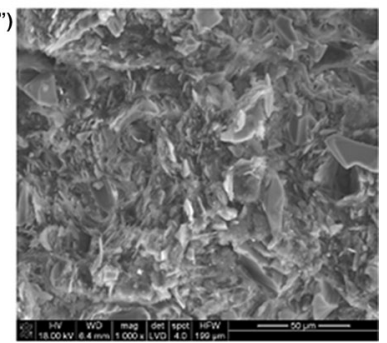

Fig. 2 Cross section micromorphology (SEM) of the composites before ceramization taken under different magnifications of $350 \times\left(a^{\prime}\right.$, $\left.b^{\prime}, c^{\prime}\right)$ and $1000 \times\left(a^{\prime \prime}, b^{\prime \prime}, c^{\prime \prime}\right)$ for: reference $(\mathbf{a})$, graphite $(\mathbf{b})$, TEA (c) 
In general, the micromorphology before ceramization is similar for all the composites showing common particular fillers/elastomer matrix arrangement. However, some morphological differences are visible for the graphite composite. Flat and relatively large graphite particles are clearly visible dispersed in the SBR matrix in-between the other filler particles. Sharply edged particles of the glass frit are also clearly visible (Fig. 2 a", b"). Due to their relatively big size, they are quite well dispersed between a filler in the elastomer matrix. However, their large particle size also results in deteriorating the tensile properties by initiating microcrack generation during the elongation of the composites.

\section{Combustibility}

The large amount of mineral fillers and glass frit incorporated into the composites facilitates the formation of the ceramic structure which exhibits good thermal barrier properties and protects the bulk of the composite material against flames and high temperature at the beginning of combustion. At higher temperature, before all polymer matrices degrade the glass frit softens and connects the additional thermally stable mica particles resulting in the formation of a continuous ceramic structure.

The lowest heat emission is exhibited by the sample without any plasticizers added (Fig. 3). It is an expected result because all plasticizers added are flammable. The key question is which plasticizers increase the combustibility of the composites to the lowest extent. Based on the cone calorimetry results, it is obvious that this plasticizer is graphite. Its incorporation results in the lowest heat emission of all the composites, with the exclusion of the reference composite. The maximum values of HRR, ARHE and THR curves for the graphite sample are the lowest from all the composites. This sample also loses the least of mass after the combustion tests. Such result was expected due to the fact that graphite platelets are widely used in
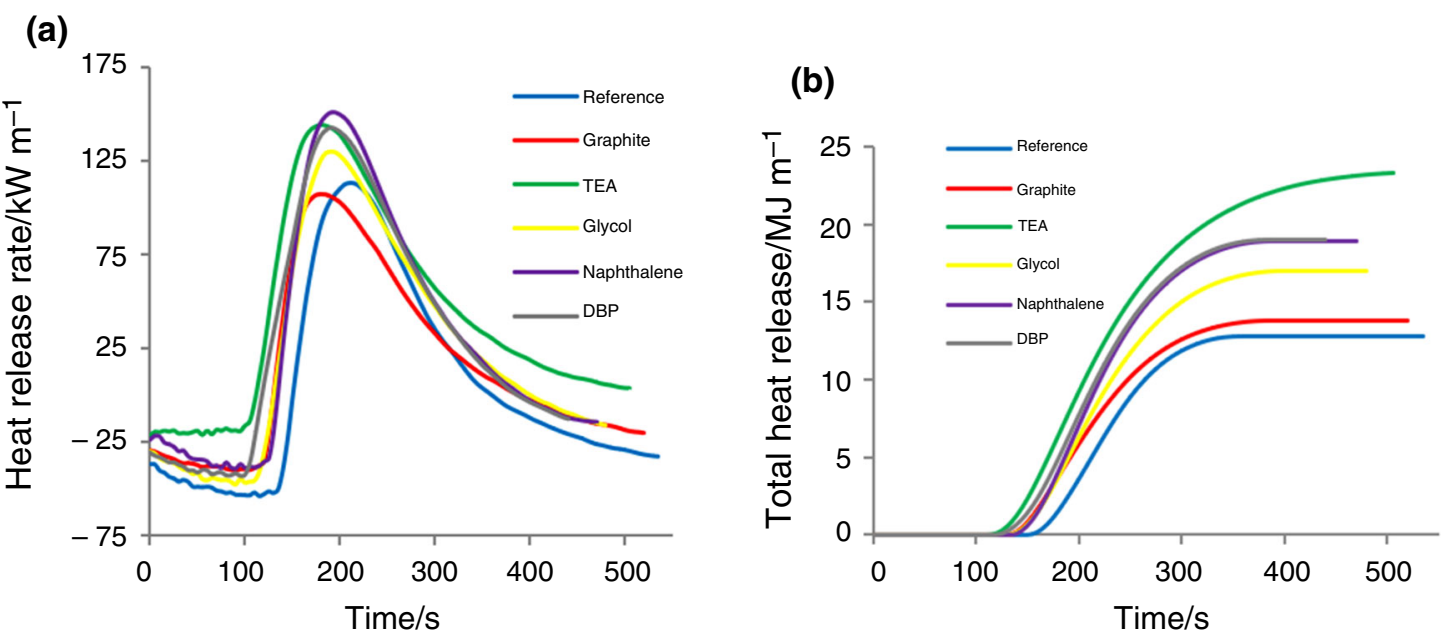

(c)

\section{(d)}
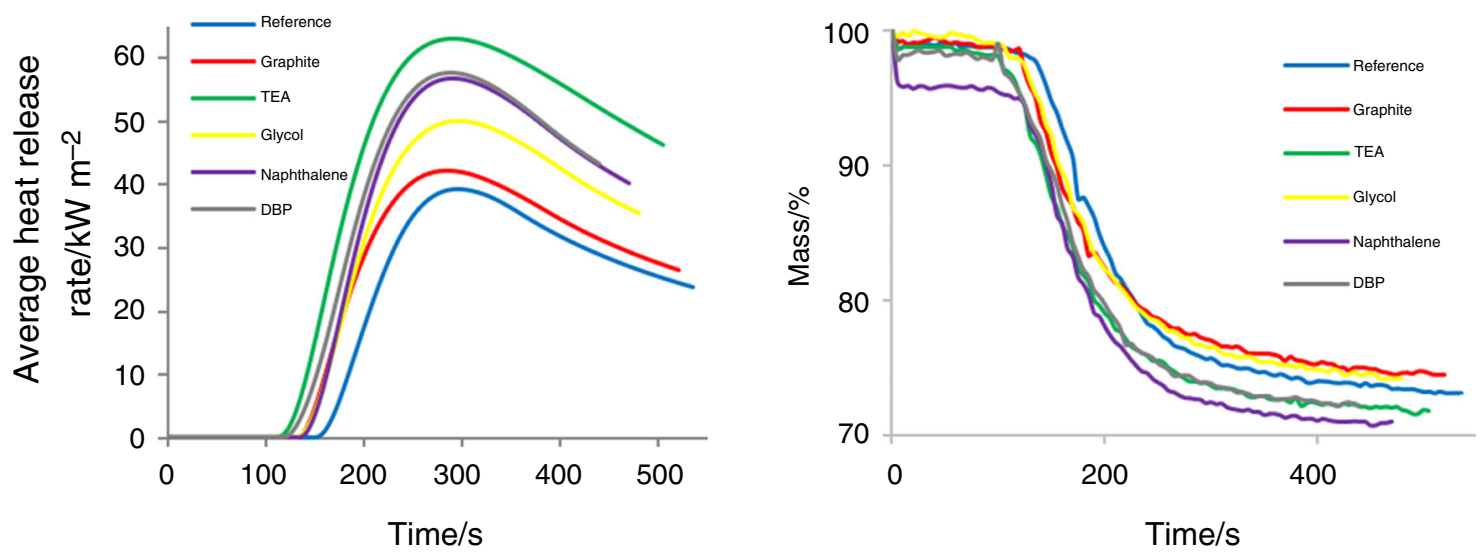

Fig. 3 Cone calorimetry analysis of the composites: heat release rate (HRR) (a), total heat released (THR) (b), averaged heat release rate (ARHE) (c) and mass loss (d) 
various flame-retardant systems for elastomers [34]. Flat and plane graphite platelets are reported to reflect the IR radiation responsible for heat spreading reducing the temperature increase rate of the composite. Therefore, the combustion processes slow down. The TEA sample exhibits the highest heat emission values, which also performed the best processability during the extrusion test. Unfortunately, this plasticizer does not improve the other crucial properties of the ceramizable composites such as their flame retardancy or mechanical properties.

In order to have a good comparative parameter between the composites, a $\mathrm{HRR}_{\mathrm{p}} / t_{\mathrm{HRR}}$ ratio was calculated (Table 3). This parameter (known also as FIGRA) is often used to compare combustibility of polymer composites based on the cone calorimetry results [19]. Therefore, by using just one parameter, one can observe how dynamic was the heat generation rate during the test and how long the sample had to be exposed to the heating IR radiators to burn with the highest efficiency. Taking into account this parameter, it could be concluded that the composite filled with graphite exhibits the best flame-retardant properties in comparison with the other composites with different plasticizers. The glycol composite exhibits also good flameretardant properties. TEA composite shows the worst flame-retardant performance.

\section{Properties of composites after ceramization}

Only the samples which broke perfectly through the center of their cross section were taken into account for the statistical calculation of compression strength. After ceramization under $950{ }^{\circ} \mathrm{C}$ and $550-1000{ }^{\circ} \mathrm{C}$ conditions, all the samples exhibit almost the same shape like before ceramization. After the thermal test under $1100{ }^{\circ} \mathrm{C}$ condition, a porous structure was formed on the surface of the composite samples. Such structure is created when a still soft and relatively plastic mix of the glass frit and mica is deformed by gases created during the polymer matrix pyrolysis in bulk of the sample. The ceramizable composites treated under the $1100{ }^{\circ} \mathrm{C}$ condition undergo vigorous pyrolysis when the temperature rises rapidly.

The graphite composite exhibits the highest compression strength (Table 4 and Fig. 4). This is because most probably not all graphite particles are burned during the ceramization. We observed similar results in our previous study, in which carbon fibers incorporated into a silicone matrix could withstood the ceramization conditions [16]. Moreover, the results of cone calorimetry show that graphite composite loses $1.5 \%$ less mass after burning than any other composite and its THR value is not significantly higher than in the case of the reference sample, suggesting that not much additional heat is released from the graphite burning. During ceramization, the graphite is most likely situated in the ceramic structure next to the mineral filler particles and therefore makes this phase stronger. Other composites exhibit compression strength at similar level to

Table 4 Compression strength of the ceramized composites studied

\begin{tabular}{lcll}
\hline Name of the composite & \multicolumn{3}{c}{ The average maximum force/N } \\
\cline { 2 - 4 } & $1100{ }^{\circ} \mathrm{C}$ & $950{ }^{\circ} \mathrm{C}$ & $550-1000{ }^{\circ} \mathrm{C}$ \\
\hline Reference & $222 \pm 32$ & $355 \pm 276$ & $162 \pm 95$ \\
Graphite & $529 \pm 273$ & $354 \pm 81$ & $311 \pm 81$ \\
TEA & $87 \pm 38$ & $334 \pm 74$ & $143 \pm 74$ \\
Glycol & $144 \pm 15$ & $176 \pm 58$ & $145 \pm 58$ \\
Naphthalene & $206 \pm 122$ & $312 \pm 153$ & $204 \pm 153$ \\
DBP & $172 \pm 71$ & $329 \pm 127$ & $151 \pm 127$ \\
\hline
\end{tabular}

Table 3 Flammability parameters: time to ignition $\left(t_{\mathrm{i}}\right)$, time to flameout $\left(t_{\mathrm{o}}\right)$, heat release rate peak $\left(\mathrm{HRR}_{\mathrm{p}}\right)$, heat release rate mean value $\left(\mathrm{HRR}_{\mathrm{m}}\right)$, time to $\mathrm{HRR}_{\mathrm{p}}\left(t_{\mathrm{HRR}}\right)$, $\mathrm{HRR}_{\mathrm{p}} / t_{\mathrm{HRR}}$ ratio, total heat released (THR), effective heat of combustion peak $\left(\mathrm{EHC}_{\mathrm{p}}\right)$, effective heat of combustion mean value $\left(\mathrm{EHC}_{\mathrm{m}}\right)$, mass los rate peak $\left(\mathrm{MLR}_{\mathrm{p}}\right)$, mass loss rate mean value $\left(\mathrm{MLR}_{\mathrm{m}}\right)$ and mass loss $\left(m_{1}\right)$

\begin{tabular}{lllllll}
\hline Parameter & Reference & Graphite & TEA & Glycol & Naphthalene & DBP \\
\hline$t_{\mathrm{i}} / s$ & 133 & 114 & 98 & 106 & 119 & 95 \\
$t_{\mathrm{o}} / s$ & 446 & 388 & 404 & 409 & 361 & 360 \\
$\mathrm{HRR}_{\mathrm{p}} / \mathrm{kW} \mathrm{m}^{-1}$ & 112.9 & 107.0 & 144.0 & 129.3 & 150.2 & 142.3 \\
$\mathrm{HRR}_{\mathrm{m}} / \mathrm{kW} \mathrm{m}^{-1}$ & 35.6 & 48.9 & 73.1 & 54.6 & 75.3 & 68.9 \\
$t_{\mathrm{HRR}} / s$ & 210 & 180 & 180 & 190 & 190 & 195 \\
$\mathrm{HRR}_{\mathrm{p}} / t_{\mathrm{HRR}} / \mathrm{kW} \mathrm{m}^{-1} \mathrm{~s}^{-1}$ & 0.54 & 0.59 & 0.81 & 0.68 & 0.79 & 0.73 \\
$\mathrm{THR} / \mathrm{MJ} \mathrm{m}^{-2}$ & 12.8 & 13.8 & 22.3 & 17.0 & 18.7 & 18.9 \\
$\mathrm{EHC}_{\mathrm{p}} / \mathrm{MJ} \mathrm{kg}^{-1}$ & 74.5 & 76.0 & 75.6 & 74.6 & 72.9 & 79.3 \\
$\mathrm{EHC}_{\mathrm{m}} / \mathrm{MJ} \mathrm{kg}^{-1}$ & 10.7 & 13.4 & 20.1 & 14.1 & 17.0 & 15.8 \\
$\mathrm{MLR}_{\mathrm{p}} / \mathrm{g} \mathrm{s}^{-1}$ & 0.180 & 0.120 & 0.130 & 0.130 & 0.167 & 0.119 \\
$\mathrm{MLR}_{\mathrm{m}} / \mathrm{g} \mathrm{s}^{-1}$ & 0.029 & 0.032 & 0.032 & 0.034 & 0.039 & 0.039 \\
$m_{\mathrm{l}} / \%$ & 24.6 & 23.3 & 26.3 & 24.3 & 24.5 & 25.7 \\
\hline
\end{tabular}


Fig. 4 Compression strength of the ceramized composites studies

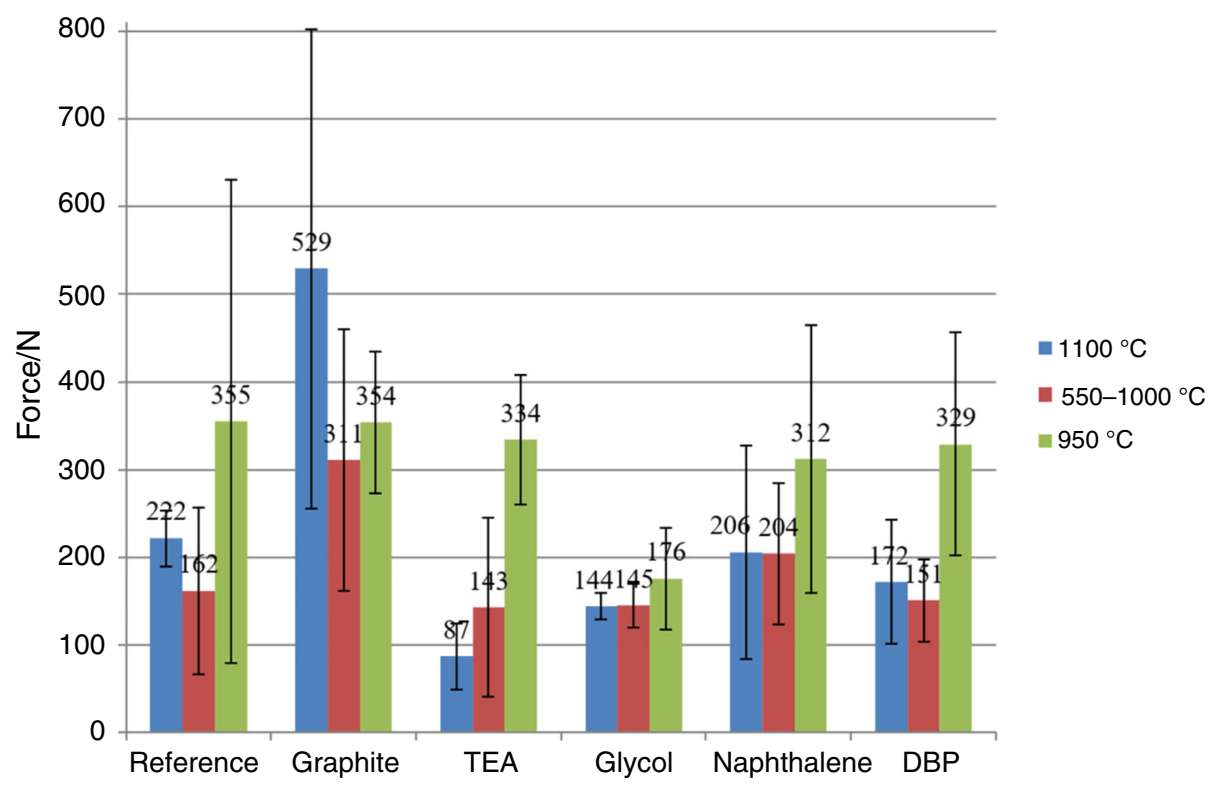

reference composite or are less durable. During the fast ceramization test, the following phenomenon was observed: if too much heat is generated during burning or pyrolysis of the elastomer matrix and additional plasticizer the glass frit is melting very fast and some part of it is flowing in the lower part of the cylindrical-shape sample. This results in poor dispersion and distribution of glass frit and mica forming a vertical gradient structure with the glass frit on the bottom and loose mica powder on the top. Such structure exhibits worse mechanical properties during the compression tests.

\section{Conclusions}

The results of this study show that the addition of even $10 \mathrm{phr}$ of a plasticizer can improve extrudability of a highly filled elastomer ceramizable composite. In the case of TEA composite, this improvement is very significant. Even for the composite in which a layered carbon fillergraphite-was incorporated as a plasticizer the flow during the extrusion is better than for the reference sample. All the plasticizers used improved the ceramizable composites' properties during extrusion. The composite filled with graphite exhibits higher strain moduli, but, on the other hand, the composite filled with TEA shows improved elasticity which can be observed in mechanical properties tests before ceramization. Graphite as a carbon filler exhibits strong interaction with SBR elastomer macromolecules. TEA reduces the interaction between mineral fillers and the matrix. Graphite shows the best overall performance as a plasticizing additive for ceramizable
SBR-based composites. The composite filled with graphite is characterized by the best properties during combustion, produces the strongest ceramic structure and also can improve the processing properties of ceramizable composites. In the graphite composite performance, a new effect of plasticizing is visible. Plasticizers are working mostly on the principle of grease by reducing filler-polymer matrix interactions. For ceramizable composites, where the fillers' content is high the main task is to reduce filler-filler interactions. In this case, graphite can act as plain bearing between flat particles of fillers. For the graphite composite, a strengthening effect is still visible, but this effect is co-working with a plasticizing effect. In the future, it is necessary to perform more tests for composites filled with graphite with different amounts of this plasticizer and to characterize changes in the dynamic viscosity in different shear rates in order to design a ceramizable SBR composite of improved processability and satisfactory flame-retardant performance. Furthermore, it is essential to research different types of fillers which can reduce fillerfiller interaction in ceramizable composites while improving the processing parameters.

Acknowledgements Sincere thanks to Martyna Kościukiewicz for providing language assistance.

Open Access This article is distributed under the terms of the Creative Commons Attribution 4.0 International License (http://creative commons.org/licenses/by/4.0/), which permits unrestricted use, distribution, and reproduction in any medium, provided you give appropriate credit to the original author(s) and the source, provide a link to the Creative Commons license, and indicate if changes were made. 


\section{References}

1. Rybiński P, Janowska G. Effect of the spatial network structure and cross-link density of diene rubbers on their thermal stability and fire hazard. J Therm Anal Calorim. 2014;117(1):377.

2. Jurkowski B, Jurkowska B, Rydarowski H. Palność materiałów polimerowych. Poznań: Wydawnictwo Politechniki Poznańskiej; 2010.

3. Rybiński P, Janowska G, Kucharska-Jastrząbek A, Pająk A, Wójcik I, Wesołek D, Bujnowicz K. Flammability of vulcanizates of diene rubbers. J Therm Anal Calorim. 2012;107:1219.

4. Marosi G, Marton A, Anna P, Bertalan G, Marosfoi B, Szep A. Ceramic precursor in flame retardant systems. Polym Degrad Stab. 2002;77:259.

5. Hanu LG, Simon GP, Cheng YB. Preferential orientation of muscovite in ceramifiable silicone composites. Mater Sci Eng, A. 2005;398:180.

6. Morgan AB, Chu LL, Harris JD. A flammability performance comparison between synthetic and natural clays in polystyrene nanocomposites. Fire Mater. 2005;29:213.

7. Delebecq E, Hamdani-Devarennes S, Raeke J, Lopez Cuesta J-M, Ganachaud F. High residue contents indebted by platinum and silica synergistic action during the pyrolysis of silicone formulations. ACS Appl Mater Interfaces. 2011;3:869.

8. Anyszka R, Bieliński DM, Pędzich Z, Parys G, Rybiński P, Zarzecka-Napierała M, Imiela M, Gozdek T, Siciński M, Okraska M, Ziąbka M, Szumera M. Effect of mineral filler additives on flammability, processing and use of silicone-based ceramifiable composites. Polym Bull. 2018;75(4):1731.

9. Feipeng L, Lihong C, Qiuying L, Ting W, Xinyuan G, Weihong $\mathrm{G}$. The combination of glass dust and glass fiber as fluxing agents for ceramifiable silicone rubber composites. RSC Adv. 2017;7:38805.

10. Feipeng L, Wei Y, Weihong G, Ting W, Quiying L. Preparation and properties of ceramifiable flame-retarded silicone rubber composites. J Therm Anal Calor. 2017;130:813.

11. Xin-Hao G, Tao-Yuan W, Jie M, Dong Z, Yu-Cai S, Ting-Wei W. Improved self-supporting property of ceramifying silicone rubber composites by forming crystalline phase at high temperatures. J Alloys Compd. 2017;706:322.

12. Bieliński DM, Anyszka R, Pędzich Z, Dul J. Ceramizable silicone rubber-based composites. Int $\mathrm{J}$ Adv Mater Manuf Charact. 2012;1:17.

13. Hanu LG, Simon GP, Cheng YB. Preferential orientation of muscovite in ceramifiable silicone composites. Mater Sci Eng, A. 2005;398:180.

14. Duan QY, Wang JP, Ren QB, Li K, Zhang ZZ, Wang YY. Effect of adding carbon fiber on conductive stability of acrylonitrilebutadiene rubber composites. J Appl Polym Sci. 2018;135:46668.

15. Guo JH, Chen XM, Zhang Y. Improving the mechanical and electrical properties of ceramizable silicone rubber/halloysite composites and their ceramic residues by incorporation of different borates. Polymers. 2018;10(4):388.

16. Anyszka R, Bieliński DM, Pędzich Z, Szumera M. Influence of surface-modified montmorillonites on properties of silicone rubber-based ceramizable composites. J Therm Anal Calorim. 2015;119:111.

17. Imiela M, Anyszka R, Bieliński DM, Pędzich Z, ZarzeckaNapierała M, Szumera M. Effect of carbon fibers on thermal properties and mechanical strength of ceramizable composites based on silicone rubber. J Therm Anal Calorim. 2016;124:197.

18. XinHao G, YuCai S, TingWei W. Improved ceramifiable properties of EVA composites with whitened and capsulized red phosphorus (WCRP). RSC Adv. 2016;6:96984.
19. Ferg EE, Hlangothi SP, Bambalaza S. An experimental design approach in formulating a ceramifiable EVA/PDMS composite coating for electric cable insulation. Polym Compos. 2017;38:371.

20. Hong-Wei D, Cong D, Rui-Min L, Liang-Ping D, Yu-Zhong W. A novel EVA composite with simultaneous flame retardation and ceramifiable capacity. RCS Adv. 2015;5:51248.

21. Li Y-M, Deng C, Long J-W, Huang S-C, Zhao Z-Y, Wang Y-Z. Improving fire retardancy of ceramifiable polyolefin system via a hybrid of zinc borate@melamine cyanurate. Polym Degrad Stab. 2018;153:325.

22. Anyszka R, Bieliński DM, Pędzich Z, Rybiński P, Imiela M, Siciński M, Zarzecka-Napierała M, Gozdek T, Rutkowski P. Thermal stability and flammability of styrene-butadiene rubberbased (SBR) ceramifiable composites. Materials. 2016;9:604.

23. Imiela M, Anyszka R, Bieliński DM, Lipińska M, Rybiński P, Syrek B. Synergistic effect of mica, glass frit, and melamine cyanurate for improving fire resistance of styrene-butadiene rubber composites destined for ceramizable coatings. Coatings. 2019;9:170.

24. Anyszka R, Bieliński DM, Pędzich Z, Zarzecka-Napierała M, Imiela M, Rybiński P. Processing and properties of fire resistant EPDM rubber-based ceramifiable composites. High Temp Mater Proc. 2017;36(10):963.

25. Zou Z, Qin Y, Liu L, Huang Z. Effect of the flux on the fireresistance properties of cerami-fiable EPDM rubber composites. Adv Compos Lett. 2018;27(3):89.

26. Rybiński P, Syrek B, Bradło D, Żukowski W, Anyszka R, Imiela M. Influence of cenospheric fillers on the thermal properties, ceramisation and flammability of nitrile rubber composites. J Compos Mater. 2018;52(20):2815.

27. Azoug A, Neviere R, Pradeilles-Duval R-M, Constantinescu A. Influence of crosslinking and plasticizing on the viscoelasticity of highly filled elastomers. J Appl Polym Sci. 2014;131(12):45500.

28. Li J, Isayev AI, Wang Q, Soucek MD. Sustainable plasticizer for butyl rubber cured by phenolic resin. J Appl Polym Sci. 2018;135(24):45500.

29. Akhina H, Mhammed Arif P, Gopinathan Nair MR, Nandakumar K, Sabu T. Development of plasticized poly (vinyl chloride)/ reduced graphene oxide nanocomposites for energy storage applications. Polym Test. 2019;73:250.

30. Akhina H, Gopinathan Nair MR, Nandakumar K, Pramoda KP, Tan HR, Lekshmi K, Sabu T. Plasticized PVC graphene nanocomposites: morphology, mechanical, and dynamic mechanical properties. Polym Eng Sci. 2017;58:E104.

31. Elizabeth F, Lindong Z, Hyun ChK, Renjith R, Amarenda G, Balerao GM, Nandakumar K, Varughese KT, Jaehwan K, Sabu T. Morphology correlated free volume studies of multi-walled carbon nanotube plasticized poly (vinyl chloride) nanocomposites: positronium probes and electrical properties. Polymer. 2018;141:232.

32. Bieliński DM, Dobrowolski O, Ślusarski L. Dyspersja napełniacza w matrycy kauczuku. Polimery. 2007;52(9):640.

33. Czajka M, Shanks RA, Kong I. Preparation of graphene and inclusion in composites with poly(styrene-b-butadiene-b-styrene). Sci Eng Compos Mater. 2013. https://doi.org/10.1515/secm2013-0119.

34. Zhang L, Wang L, Fischer A, Wu W, Drummer D. Effect of graphite on the flame retardancy and thermal conductivity of P-N flame retarding PA6. J Appl Polym Sci. 2018. https://doi.org/10. 1002/app.46559.

Publisher's Note Springer Nature remains neutral with regard to jurisdictional claims in published maps and institutional affiliations. 


\section{Affiliations}

\section{Mateusz Imiela ${ }^{1}$ (D) Rafał Anyszka, ${ }^{1,2}$ Dariusz Mariusz Bieliński ${ }^{1} \cdot$ Marcin Masłowski $^{1} \cdot$ Zbigniew Pędzich $^{3}$.} Magdalena Ziąbka ${ }^{3}$ Przemysław Rybiński ${ }^{4} \cdot$ Bartłomiej Syrek $^{4}$

1 Institute of Polymer and Dye Technology, Faculty of Chemistry, Lodz University of Technology, Stefanowskiego 12/16, 90-924 Lodz, Poland

2 Department of Mechanics of Solids, Surfaces and Systems (MS3), Chair of Elastomer Technology and Engineering, Faculty of Engineering Technology, University of Twente, Enschede, The Netherlands
3 Department of Ceramics and Refractory Materials, Faculty of Material Science and Ceramics, AGH - University of Science and Technology, Al. Mickiewicza 30, 30-045 Kraków, Poland

4 Department of Environmental Protection and Modeling, The Jan Kochanowski University in Kielce, Kielce, Poland 